\title{
Analysis on Structure of National Exhibitions of Fine Arts from 1949 Guang-Zhi FANG
}

\author{
Room 401, South Longhu Lane \# 72, Xiamen (postcode:361005), Fujian,China.
}

787005777@qq.com

\begin{abstract}
Keywords: National Exhibition of Fine Arts; Main Structure; Thematic Arts
\end{abstract}
\begin{abstract}
All previous National Exhibitions of Fine Arts held after the new China founded were regarded as one of the spirit carriers to reflect the national interests, consistent with the ideological trend of the dominant culture and followed, and subject to the universal values of social culture and the natural law of art development. The National Exhibition of Fine Arts has a special meaning and plays a special function to the development of socialist culture, and this can be found from the supports provided and the cultural mechanism implemented by the government. A new logical starting point will always be found in the trend of thought in literature and art for the values and practical significances in each stage. The National Exhibition of Fine Arts had confirmed the humanity spirits rooted in the traditional culture which had and will be improved and perfected in this way.

As with the major thematic art creating activities, the National Exhibition of Fine Arts is one of the important forms for constituting the main cultural structure in the fine art domain. From the First National Exhibition of Fine Arts in 1949, the Ministry of Culture of the P.R.C. and China Artists Association had cosponsored, if so defined, the National Exhibitions of Fine Arts up to 11 times during a period more than 60 years. In fact, if defined as "national comprehensive exhibition of fine arts", three exhibitions held in the era of Republic of China and two exhibitions during the Great Cultural Revolution shall be included.
\end{abstract}

\section{Four National Exhibitions of Fine Arts before the Great Cultural Revolution}

The "National Exhibition of Fine Arts" which was sponsored during the First National Writers and Artists Conference in 1949 was the first one held after the foundation of the new China. Three national exhibitions of arts had been held before 1949, and the early curator systems and criticism of art had been initiated simultaneously. In many of his speeches and works during the era of Republic of China, Cai Yuanpei had indicated the significances of holding such exhibitions of arts to the artistic accomplishments and aesthetic educations of the public. In 1928, when he held the post of Minister of the Ministry of Education \& Research of the Republic of China, he decided to hold a national exhibition of arts in Shanghai. As early as 1922, Liu Haisu, Cai Yuanpei and Zhang Junli had discussed and drafted a proposal concerning the exhibitions of arts to be held by the government and planned to submit this proposal during the first convention of the China Education Association to be held on July 3.[1] on August 18, 1925, the proposals had been discussed on the first meeting of the aesthetic education group from the annual meeting of the China Education Improvement Society to prepare and establish a national art gallery, to hold the national exhibition of fine arts, and to prepare and organize a national fine arts exhibition committee, and 17 persons, including Wang Yachen, Cai Yuanpei, Liu Haisu, Wang Jiyuan, Li Yishi, Wang Yuezhi, Teng Gu, Yu Jifan and Qian Taosun had been selected as the committee members. [2]In this stage, there were three kinds of the curators, namely the fine arts exhibition planners: the first kind was the government officials with high prestige in the public, such as Cai Yuanpei, Jiang Menglin, etc.; the second kind was the entrepreneurs who got deep pockets, possessed passions of arts, affected by the modern trends of western thought, and were active in the public facilities and services, such as Chen Xiaodie, Wang Yiting, etc.; and the third kind was from the aspiring young people who had the backgrounds of study abroad or study tour and held a positive attitude to the modern fine arts 
exhibitions in China, such as Xu BeiHong, Lin Fengmian, Lin Wenzheng, Liu Haisu, etc., who had constituted the hard core of the aesthetic education of the public. In 1929, the Ministry of Education of the previous Republic of China had sponsored "The First National Fine Arts Exhibition", which had a epoch-making meaning; This exhibition had initiated and got lots of experiences from the combination of the fine arts of modernist school with various of modern and up-to-date exhibitions after the artistic innovation during the May 4th Movement, and such a mode, utilizing and supported by the whole nation to hold the national arts exhibition, had been inherited and continued for nearly a century to this date. This was the first comprehensive fine arts exhibition sponsored by the government of the previous Republic of China for the general public. This exhibition was held in the Xin $\mathrm{Pu} \mathrm{Yu}$ Tang in Shanghai and had brought forth the emergence of the early criticism of arts. The first national fine arts exhibition had displayed the art works in a very extensive range, including painting and calligraphy, inscriptions, western paintings, sculptures, architecture, industrial arts, photography, etc., and the splendor of the occasion surpassed anything heretofore seen.

From April 1 to 23, 1937, the second national fine arts exhibition was held at the art museum newly built in Nanjing, and the sponsor was the Ministry of Education of the previous Republic of China. Qin XiaoFu had proposed in his "Expectations to the Second National Fine Arts Exhibition" that "Firstly, expect that such exhibition shall be held regularly other than occasionally. Once in a year will be preferred, with date of start and duration predetermined so as to hold on schedule. ... Secondly, expect that what will be displayed in the next exhibition shall be the works of the contemporaries, and the national fine arts exhibition shall be an artistic activity of the contemporaries, with the antique things exhibited in the Palace Museum continuously, or, if stored up by privates, to be collected by the Palace Museum or art gallery for exhibiting from time to time. ... Thirdly, expect that the preparatory committee members and the censors shall be divided into two independent groups at the time of disclosing before the start of the next exhibition. ... Fourthly, expect that additional awards, including money and medals, shall be provided for the next exhibition". [3]The extensive contents of this exhibition could be classified into nine categories, including books, inscriptions, arts, crafts, architectural drawings and models, sculptures, western paintings, modern calligraphy and paintings, calligraphy and paintings of the past dynasties and photography works, which had been recorded in the exhibit collections published after the exhibition, with Xue Quanzeng as the editor in chief. These collections had been prepared in three categories: A. collection of calligraphy and paintings by the masters in the dynasties of Jin, Tang, Five Dynasties and Ten Kingdoms, the dynasties of Song, Yuan, Ming and Qing; B. collection of modern calligraphy and paintings; $C$. collection of modern western paintings, designs and sculptures.

The third national fine arts exhibition had been held in Chongqing during December 15, 1942 to January 1, 1943, i.e. during the period of the War of Resistance against Japan. Zhang Daofan was designated as the censor in chief, with Chen Shuren as the deputy censor in chief, and 6 units had been invited to participate this exhibition, including the National Beiping Palace Museum, History and Chinese Research Institute of the National Central Research Institute, National Central Museum Preparatory Office, arts and antiques study group from the Ministry of Education and Division of Construction. There were 1,688 works received from 960 participators from 14 provinces all over the nation, wherein, approximately 300 works were delayed due to the traffic disruption. From 1941 to 1945, the Ministry of Education had set aside a special fund as the incentives for the excellent creations of arts, and accordingly, the good pieces from the third national fine arts exhibition had been planned into the annual awards.

604 pieces in total had been exhibited on the National Exhibition of Fine Arts held in 1949. Many brilliant thematic creations had emerged during the Second National Exhibition of Fine Arts held in 1955 to reflect the major themes of the early years of the new nation, such as the Founding Ceremony by Dong Xiwen, Tunnel Warfare by Luo Gongliu, etc. According to an editorial, "To strive for further prosperity and enhancement of our arts", of the People's Daily, "more than 90 
times of exhibitions and observation tours had been held by the provinces and cities all over the nation in 1954". [4]The "National Exhibition of Fine Arts for Celebrating the 20th Anniversary of the Mao's Speech at Yan'an Forum on Literature and Art" held in 1962, namely the third National Exhibition of Fine Arts, [5] and the fourth National Exhibition of Fine Arts held from 1964 to 1965 had intensively displayed the achievement of paintings reflecting the history before and after 1960, such as Bloody Shirt by Wang Shiguo, Image of Du Fu by Jiang Zhaohe, Nan Ni Wan by Zhang Ziyi and other excellent pieces which had reflected the overall creating level of Chinese arts in that stage. Comments had been published in the magazine "ART" in series, such as "New achievement of socialist arts" [6]"Be the sharp knife for the class struggle", [7]"To play roles in the revolutionary war of arts", etc. for the National Exhibition of Fine Arts held in 1965. [8]The article "Look back and forward into the National Exhibition of Fine Arts" was published in the ART; "from September 1964 to July 1965, the National Exhibition of Fine Arts had been held in Beijing. 2025 pieces of works from 26 provinces (regions) and two municipalities had been exhibited according to the regions and in several stages, and this Exhibition will last nine months (in exhibition tour at present). ... The visitors had been up to 320 thousand person-times during the exhibition in Beijing. [9] The methodology of "Three in One", i.e. directions from leaders, skills from artists and subjects from common people, had been implemented in the creation of these fine arts, in addition to the requirements of continuously developing and expanding the team of artists in a more revolutionary way". Certain of signs of the Great Cultural Revolution could be observed from such claims easily.

\section{Two Exhibitions during the Great Cultural Revolution}

The "National Exhibition of Fine Arts for Celebrating the 30th Anniversary of Chairman Mao's Speech at Yan'an Forum on Literature and Art" held in 1972 had mainly displayed the mass outcomes of arts after the start of the Great Cultural Revolution, such as "Chairman Mao Visiting Anyuan", "Chairman Mao Visiting the Countryside of Guangdong", etc. The "National Exhibition of Fine Arts for Celebrating the 25th Anniversary of the Foundation of the People's Republic of China" held from October 1, 1974 was another comprehensive exhibition of fine arts, which had revealed a certain of tendency of diversification in the themes. Three exhibitions all over the Chinese People's Liberation Army had been held before 1965: the first exhibition, "Exhibition of Fine Arts for Celebrating the 30th Anniversary of the Foundation of the PLA" started on August 1, 1957; the second, "The Second Exhibition of Fine Arts of the Whole PLA", started on January 28k, 1960; "Exhibition of Fine Arts of the Navy" held in Beijing in August 1959; and the "Exhibition of Fine Arts of the PLA's Troops in Kunming" held in February 1963. Three exhibitions of arts had been held by the troops in Nanjing before 1962. In 1964, Premier Zhou had visited the Third National Exhibition of Fine Arts of the PLA. [10]

In our history, these fine arts on the military materials and themes had generated profound influences in those special stages, had expanded the visual experiences and improved the inner accomplishment by abundant materials for the realm of spirits, and in particular, the constructing of grand landscapes, the building of images and the demonstrating of scenarios in the military fine arts reflected the values and significances of the social history and beyond the art itself, to vividly record the pictures from the historical transition of the society and the politics.

\section{National Exhibitions of Arts after the Reform and Opening-up}

Since the Third Plenary Session of the 11th Central Committee of the Chinese Communist Party, the policies implemented by the Chinese Communist Party concerning the literature and arts had been adjusted materially, to define the general objective of the tasks in connection with the literature and arts as "literature and arts to serve the people and socialism", which was not only a historical transition of the guidelines applied to the literature and arts but also a milestone of transition of the mainstream culture. In the early 1980, the "Scar arts" reflecting the policy of "rectify all reversals of right and wrong" had constituted the major of the fifth National Exhibition of Fine Arts, and the 
traditional Chinese painting, "The premier and his people", by Zhou Sicong had won the first prize. "Total 417 pieces from 480 creators from the nation had been exhibited, including 106 traditional Chinese paintings, 54 sculptures, 79 graphic arts and 46 pieces of other works, which were the initial outcomes produced in the last three years by the common artists under the guidance of the Double Hundred Policies, by making their efforts upon freeing their minds, when the nation was led by the CCP to step in the new Long March of fulfilling the Four Modernizations".[11]

The Sixth National Exhibition of Fine Arts held in 1985 had not broken through the structure: except for the necessary thematic works, the themes and materials concerning "Rural Arts" accounted for a considerable proportion. In addition, certain of "Scar" topics had been displayed in this Exhibition, such as "The generation like us" by Chen Yiming, Youth by He Duoling, etc. Some works belonging to the modern art had been found during the "Exhibition of Arts of Advancing Youth in China" held in the same year. [12] The "Exhibition of Arts of Chinese Sports Culture" was held in July of 1985, in which year Beijing had held an exhibition of fine arts of the teachers from the nationwide institutions of higher education of arts, with an editorial published for it with the subject "The society is expected to attach more importance to aesthetic education". [13]

The Seventh National Exhibition of Fine Arts held in 1989 was a very special exhibition which had shown the matured and cool attitudes of the mainstream culture in front of a more complex situation, as stated as "is a great review on the development of the traditional Chinese paintings of this generation, or is a milestone for the traditional Chinese paintings of this generation to come into a new stage", [14]and "this Exhibition is lack of dramatic oil paintings". [15]In the following Exhibitions, the works were at the same level, and there were few masterpieces in addition to relatively fixed structure. As for the Eighth National Exhibition of Fine Arts, the gold, silver and bronze had been replaced by the uniform honorable mention, partially because of lacking of outstanding pieces and partially, maybe, related to the current political environment. The Ninth, Tenth and Eleventh National Exhibitions of Fine Arts focused on different themes, while the Eighth National Exhibition of Fine Arts was subject to the theme "New exhibition and new requirements". [16]

The Ninth National Exhibition of Fine Arts held in 1999 encountered the grand celebration of the 50th Anniversary of Foundation, and accordingly the thematic works reflecting major events had been highlighted in this Exhibition. [17] A considerable proportion of this Exhibition was the products in connection with the military and the society fighting against the flood in 1998. The period of the Tenth National Exhibition of Fine Arts held in 2004 was close to the historical world event of celebrating the 60th anniversary of victory in the struggle against fascism, and this topic could be found in the work won the gold award, "Nanjing at 9:00 on September 9, 1945". "Various topics, abundant forms, different styles, rich meanings and self affirmation".[18] The most recent Eleventh National Exhibition of Fine Arts was held in 2009, when China had already stepped into the new stage of "development upon scientific bases" and "build a harmonious society". In fact, the National Exhibitions of Fine Arts of any stage can be regarded as the important carriers of the mainstream culture. In light of this essential nature, such exhibitions have to assume the responsibilities of guiding the aesthetic appreciation or even the values of the public, in addition to reflecting a certain artistic level. Therefore, the review and evaluation on the works in each National Exhibition of Fine Arts shall subject to the politics, ethics and other standards in addition to the confined academic standards. Simultaneously, it would be felt that the National Exhibition of Fine Arts was so steady, so plain, so lacking in initiative and overcautious, and so short of things attractive and outstanding, or even fell into a mode of just putting pieces together, which might be the effective embodiment of the mainstream culture, but some certain limitations had been applied to the individualization of the arts.

As for the organization and operation, the National Exhibition of Fine Arts is always sponsored jointly by the Ministry of Culture of the P.R.C. and the China Artists Association, and the works are all filtered by the county, municipal and provincial governments, so that the will of the government plays the crucial leading role during the whole exhibition, to show in all aspects the combination of 
the arts and the politics or culture of the nation in a certain historical stage. On one hand, the "theme" reflects the ideologies of the rulers, the benefits and interests of the whole nation; on the other hand, the development under "diversification" is subject to the universal laws applied to the literary and artistic creations and developments, and this is the only way to go with the tide of historical development. The creations upon the major themes are regarded as the "theme", and the works reflecting the lives of people, depicting the social realities, or other portraits, landscapes and still lives far from the "theme" are essential to the diversification of artistic creations. The diversifications shown in each Exhibition can be explained as the diversity in styles, the various but different locations of the participators, the extensive topics and different skills, which had been and will be the essential parts to reflect the nationwide nature of the National Exhibitions of Fine Arts.

\section{Conclusions}

As the major carriers of the mainstream culture, the structures of the National Exhibitions of Fine Arts have to present the values and manners of the "mainstream". As an important cultural event supported and sponsored by the government, the National Exhibition of Fine Arts has a relatively stable and standard mode, which is consistent with the expectations of the public in aesthetic needs. From the themes or topics of the works, it can be found that the creations of the thematic arts were incorporated with the ideologies of the rulers and constituted the core of each National Exhibition of Fine Arts. The "non-thematic" parts, however, other than the thematic creations, may be the parts providing the previous National Exhibitions of Fine Arts with distinguishable and fresh natures, since the non-thematic works possessed more consciousness in representing the unique features of an era and the social feelings which can be regarded as a demonstration by the new fine arts to those from the mainstream, and in this way, the mainstream culture had been broadened and provided with high compatibility.

\section{References}

[1] Wang Zhen,,Chronological Table of Fine Arts in Shanghai, Shanghai Painting and Calligraphy Press, Shanghai ,2005,pp.122.

[2]Shun Pao, August 18, 1925.

[3]Supplement of Art \& Literature, Ta Kung Pao .Vol.319,April 4, 1937.

[4]Chinese Artists Association,ART ,Vol.5,1955,pp.5.

[5]Chinese Artists Association,ART ,Vol.4,1962,pp.2.

[6]Chinese Artists Association,ART ,Vol.1,1965, pp.1.

[7]Chinese Artists Association,ART ,Vol.3,1965,pp.10.

[8]Chinese Artists Association,ART ,Vol.6,1965,pp.38.

[9]Chinese Artists Association,ART ,Vol.6, 1965,pp.31.

[10]Chinese Artists Association,ART ,Vol.4,1964,pp3.

[11]Chinese Artists Association,ART,Vol.3,1980, pp.10.

[12]Chinese Artists Association,ART ,Vol.7,1985,pp.14.

[13]Chinese Artists Association,ART, Vol.11,1985, pp.4.

[14]Chinese Artists Association,ART,Vol.8, 1989, pp.6.

[15]Chinese Artists Association,ART,Vol.9,1989,pp.4. 
[16]Chinese Artists Association,ART,Vol.5,1995, pp.38.

[17]Chinese Artists Association,ART, Vol.11,1999,pp4.

[18]Chinese Artists Association,ART,Vol.10, 2004,pp8. 